\title{
Red blood cell distribution width: a determinant of hospital mortality in pancreatitis
}

\author{
Payman Moharamzadeh', Kavous Shahsavari Nia ${ }^{2}$, Mohammadhossein Somi ${ }^{1}$, Mahboub Pouraghaei ${ }^{1}$, \\ Akbar Fadaeihaghi ${ }^{3}$, Farzad Rahmani ${ }^{2}$
}

'Gastrointestinal and Liver Disease Research Center, Tabriz University of Medical Sciences, Tabriz, Iran

${ }^{2}$ Road Traffic Injury Research Center, Tabriz University of Medical Sciences, Tabriz, Iran

${ }^{3}$ Student's Research Committee, Tabriz University of Medical Sciences, Tabriz, Iran

\begin{abstract}
Received: 21 July 2017
Accepted: 18 September 2017

Published online: 28 September 2017

*Corresponding author: Farzad

Rahmani, Emergency Medicine

Department, Sina Medical Research

and Training Hospital, Tabriz University

of Medical Sciences, Tabriz, Iran.

Tel: 00984135498144 ;

Fax: 00984135412151

Email: Rahmanif@tbzmed.ac.ir

Competing interests: None.

Funding information: None.

Citation: Moharamzadeh $\mathrm{P}$, Shahsavari Nia K, Somi MH, Pouraghaei M, Fadaeihaghi A, Rahmani F. Red blood cell distribution width: a determinant of hospital mortality in pancreatitis. Journal of Emergency Practice and Trauma 2018; 4(1): 34-38. doi: 10.15171/jept.2017.26.
\end{abstract}

\begin{abstract}
Objective: In recent years, there has been a great attention concerning red blood cell distribution width (RDW) in clinical decisions as well as determining the severity of diseases. This study was conducted to evaluate the primary level of RDW to predict hospital mortality in pancreatitis.

Methods: This was a descriptive analytical study performed on 100 patients with acute pancreatitis in the emergency department of Imam Reza hospital of Tabriz University of Medical Sciences. In this study, the primary level of RDW in patients with acute pancreatitis presenting to the emergency ward was collected and after patients' admission we followed them. Also, the admission outcome (mortality or discharge) of patients was registered, and finally we evaluated the predictive value of RDW in determining the patient's outcome in hospital.

Results: In our study, 47 patients were male, and 53 patients were female. Mean RDW in patients was $13.82 \pm 1.69$. Five patients died during the study. Mean RDW in dead patients and other patients was $16.44 \pm 4.22$ and $13.68 \pm 1.37$, respectively $(P<0.001)$. The cutoff point of 14.55 for RDW with $80 \%$ sensitivity and $85 \%$ specificity was determined for predicting mortality in patients.

Conclusion: Based on our study results, the initial RDW level is an independent factor for predicting in-hospital mortality in pancreatitis but not for determining the need for surgery or admission to the intensive care unit (ICU).

Keywords: Pancreatitis, Mortality, Prognosis
\end{abstract}

\section{Introduction}

The clinical symptoms of the inflammatory disease of the pancreas, also called acute pancreatitis, may be only a mild abdominal pain or a severe disease is accompanied with lower blood pressure, metabolic disorders, sepsis, third spacing, organ failures, and shock (1). This is one of the most frequent surgical emergencies. It is a mild to severe, self-limiting, and sometimes fatal disorder. The mortality rate of acute pancreatitis is variable and has a range from $3.8 \%$ to $40 \%$ (2). Early diagnosis of pancreatitis and immediate initiation of treatments to decrease the mortality rate is critical (3).

In recent years, there has been much attention concerning red blood cell distribution width (RDW) in clinical decisions as well as determining the severity of diseases $(4,5)$. The normal reference value of RDW is $12.8 \% \pm$ $1.2 \%$ if reported in CV and $42.5 \pm 3.5$ if reported in SD. The quantitative variation in the size of circulating red blood cells (RBCs) is RDW. High values of RDW show a high variation in the size of circulating RBCs and may indicate various pathological conditions. Lower values of RDW statistically show higher uniformity of size in RBCs, although they are not clinically significant (5-8). In wellestablished diseases, such as iron deficiency anemia, where the cells have uniformly been microcytic, RDW may reach the normal range. If, however, the treatment with iron begins, and the body responds to the treatment, RDW increases production of new normocytic cells until the treatment is completed, and normal hematopoiesis begins, where RDW returns to its normal range. RDW increases in other hematopoietic diseases, such as megaloblastic anemia, but it is normal in thalassemia $(5,6)$.

\section{Objectives}

As an easy and cost-effective method, the measurement of RDW is routinely used as a part of complete blood 
count (CBC) test to assess patients. Recent studies have shown the significant value of RDW in the prediction of the mortality rate in patients admitted to the intensive care unit (ICU), patients with cardiovascular diseases, and community-acquired pneumonia. This study was conducted to evaluate the primary level of RDW which was checked in the emergency ward for predicting the hospital mortality in pancreatitis.

\section{Methods}

This descriptive-analytical study was performed on 100 patients with acute pancreatitis in the emergency department of Imam Reza medical research and training hospital, Tabriz, East Azerbaijan, Iran. This hospital had an annual admission of 110000 patients from January 2014 to December 2014. The inclusion criteria included all patients admitted to the emergency ward with acute pancreatitis. We excluded patients with a positive history of anemia (iron, folate, or B12 deficiency), patients with hemolytic anemia, patients with liver disease, and patients who did not consent to participate in the study (Figure $1)$. We used the sensitivity (48\%) and specificity (96\%) of RDW in prediction of mortality that was reported in Senol and colleagues' study (4). In order to determine the sample size, with consideration the $1 \%$ prevalence of pancreatitis, $80 \%$ power, and $95 \% \mathrm{CI}$, we used Dr. Lin Naing software (9). Sampling strategy was convenient method to reach final sample size.

All patients who went to the emergency ward and met the inclusion criteria were examined in this study. Upon admission, demographic specifications (including sex, age, symptoms, and signs) of the patients who complained of acute abdominal pain and were highly suspicious of having pancreatitis (symptoms such as nausea, vomiting, and epigastric tenderness) were recorded. Then, blood samples were delivered to the laboratory to measure their serum amylase and RDW. The serum amylase was measured using a photometer (Biotecnica BT- 3000, Italy), and RDW was measured using micromachining technology (Automated Hematology Analyzer, Japan). The normal level of serum amylase and its unit of measurement were respectively up to 100 and IU/L; the normal level of RDW and its unit of measurement were respectively 13.2 and percent. For confirming the diagnosis, we performed CT scan of the abdomen and pelvis with oral and intravenous contrast (Siemens SOMATOM Emotion 6, Germany) for all patients. All CT scans were reported by a radiologist, a faculty member of that university. All patients with acute pancreatitis were admitted to the ward, and the outcomes such as mortality, the incidence of complications, and the need for surgery were assessed. Also, we calculated Acute Physiology and Chronic Health Evaluation (APACHE) II score.

The obtained data were entered into SPSS 17.0 (SPSS Inc, Chicago). To describe the data, we used descriptive

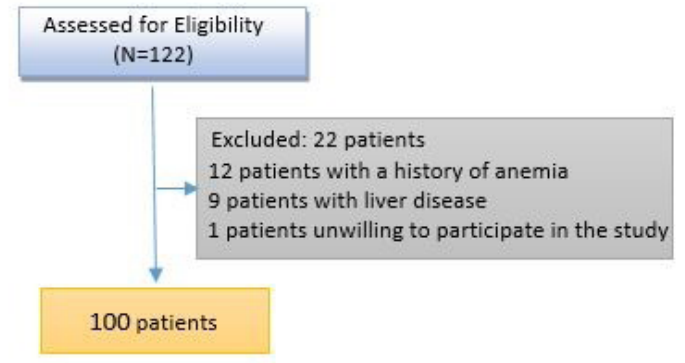

Figure 1. Study flowchart.

statistical analysis (frequency, percentage, mean $\pm \mathrm{SD}$ ). To compare quantitative data, we used $t$ test and the ROC (receiver operating characteristic curve) was used to measure area under curve (AUC), sensitivity, specificity, positive predicting value (PPV), negative predicting value (NPV), Youden index (J), and cut-off point of RDW and APACHE II score for determining the need for surgery, admission to ICU, admission complication, and mortality. In all cases, the $P$ value $<0.05$ was considered significant.

\section{Results}

We evaluated 100 patients with acute pancreatitis in this study. Of the patients, 47 were male, and 53 were female. The mean \pm SD of the age of all patients was $56.31 \pm 16.80$ years. About 26 patients had experienced gallstones. Mean duration of nil per os (NPO) in patients was 3.6 \pm 1.4 days. The mean \pm SD of the duration of hospitalization was $6.47 \pm 2.48$ days. During the hospitalization, 14 patients needed to be admitted to ICU, 5 patients died (due to surgery complications, sepsis, and acute tubular necrosis), 5 patients needed surgery (due to necrotizing pancreatitis or gallbladder stones), and 10 patients had admission complications (intubation, sepsis, and mortality). Table 1 shows vital signs and paraclinical findings of the patients. Table 2 shows mean $( \pm S D)$ of RDW and APACHE II score of patients based on admission to ICU, surgery need, admission complication, and mortality and comparison of them between groups. As shown in Table 2, there was a significant statistical difference between RDW and APACHE II score in patients who had admission complication and in-hospital mortality.

For predicting the admission complication in patients, we used the ROC curve to determine the value of RDW and APACHE II score. Figure 2A shows the predicting value of RDW for admission to the ICU, as the AUC was 0.81 for RDW and 0.78 for APACHE II score. The cut-off point of 13.95 for RDW ( $80 \%$ sensitivity, $71 \%$ specificity, 0.51 Youden index, $0.73 \mathrm{PPV}, 0.78 \mathrm{NPV}, 2.75 \mathrm{LR}+$, and 3.55 LR-) and 8.5 for APACHE II score (90\% sensitivity, 67\% specificity, 0.57 Youden index, 0.74 PPV, $0.87 \mathrm{NPV}$, 2.72 LR+, and 6.7 LR-) was determined for predicting admission complications in patients. Figure $2 \mathrm{~B}$ shows the predictive value of RDW and APACHE II score for 
Table 1. Vital signs and paraclinical findings of the patients

\begin{tabular}{|c|c|c|c|}
\hline Variables & Minimum & Maximum & Mean \pm SD \\
\hline Systolic blood pressure (mm Hg) & 90 & 185 & $125.94 \pm 16.57$ \\
\hline Diastolic blood pressure $(\mathrm{mm} \mathrm{Hg})$ & 60 & 100 & $76.31 \pm 9.92$ \\
\hline Heart rate, bpm & 60 & 115 & $82.66 \pm 9.32$ \\
\hline Respiratory rate (per minute) & 12 & 24 & $16.48 \pm 1.77$ \\
\hline RDW (\%) & 11.20 & 23.80 & $13.82 \pm 1.69$ \\
\hline APACHE II score & 1 & 25 & $7.94 \pm 3.69$ \\
\hline BUN (mmol/L) & 6.00 & 109.00 & $19.04 \pm 12.94$ \\
\hline $\mathrm{Cr}(\mathrm{mg} / \mathrm{dL})$ & 0.50 & 13.50 & $1.2030 \pm 1.30$ \\
\hline $\mathrm{BS}(\mathrm{mg} / \mathrm{dL})$ & 76.00 & 1299.00 & $156.27 \pm 135.79$ \\
\hline Amylase (IU/L) & 57.00 & 6500.00 & $1417.28 \pm 1357.41$ \\
\hline ALT (IU/L) & 8.00 & 1110.00 & $112.22 \pm 151.88$ \\
\hline AST (IU/L) & 12.00 & 1211.00 & $89.65 \pm 143.00$ \\
\hline ALP (IU/L) & 83.00 & 1586.00 & $351.33 \pm 280.38$ \\
\hline LDH (IU/L) & 201.00 & 2553.00 & $509.63 \pm 288.08$ \\
\hline $\mathrm{Ca}^{++}(\mathrm{meq} / \mathrm{L})$ & 0.10 & 10.80 & $8.68 \pm 1.13$ \\
\hline Total Bilirubin (mg/L) & 0.20 & 24.00 & $2.52 \pm 3.22$ \\
\hline $\mathrm{HCO} 3(\mathrm{mmol} / \mathrm{L})$ & 9.00 & 32.10 & $19.52 \pm 5.16$ \\
\hline $\mathrm{PaCO} 2(\mathrm{~mm} \mathrm{Hg})$ & 18.40 & 58.00 & $33.61 \pm 9.13$ \\
\hline $\mathrm{pH}$ & 7.16 & 7.54 & $7.36 \pm 0.08$ \\
\hline
\end{tabular}

Table 2. Mean ( \pm SD) of RDW and APACHE II score of patients

\begin{tabular}{llll}
\hline Variables & Frequency & RDW $(\boldsymbol{P}$ value $)$ & APACHE II score $(\boldsymbol{P}$ value $)$ \\
\hline Admission to ICU & & & $9.28 \pm 3.91$ \\
Yes & 14 & $14.33 \pm 1.26$ & $7.72 \pm 3.63(0.142)$ \\
No & 86 & $13.74 \pm 1.75(0.230)$ & $8.80 \pm 1.79$ \\
Need for surgery & & & $7.89 \pm 3.76(0.596)$ \\
Yes & 5 & $13.78 \pm 9.33$ & $11.00 \pm 2.94$ \\
No & 95 & $13.82 \pm 1.73(0.954)$ & $7.60 \pm 3.62(0.005)$ \\
Admission complication & & & $15.61 \pm 3.13$ \\
Yes & 10 & $13.62 \pm 1.34(<0.001)$ & $15.20 \pm 6.38$ \\
No & 90 & & $7.56 \pm 3.11(<0.001)$ \\
Mortality & 5 & $16.44 \pm 4.22$ & $13.68 \pm 1.37(<0.001)$ \\
Yes & 55 & & \\
No & 95 & \\
\hline
\end{tabular}

Abbreviations: ICU: intensive care unit, RDW: red cell distribution width, APACHE II: Acute Physiology and Chronic Health Evaluation.

mortality in patients with acute pancreatitis, as the AUC was 0.81 for RDW and 0.88 for APACHE II score. The cut-off point of 14.55 for RDW (80\% sensitivity, 85\% specificity, 0.65 Youden index, 0.84 PPV, 0.81 NPV, 5.33 $\mathrm{LR}+$, and 4.25 LR-) and 9.5 for APACHE II score (80\% sensitivity, 69\% specificity, 0.49 Youden index, 0.72 PPV, 0.77 NPV, 2.58 LR+, and 3.45 LR-) was determined for predicting mortality in patients.

\section{Discussion}

Various scores were used to determine mortality or incidence of complications in patients with pancreatitis, including APACHE II score, Ranson criteria, and level of serum C-reactive protein (CRP). These scores, except CRP, are obtained through collecting various data in a time-consuming process and need complicated calculations (10-13). The level of RDW has been recently introduced for prediction of mortality rate in patients with pancreatitis $(5,14,15)$.

Acute pancreatitis is mostly self-limiting, is accompanied with/out complications, and has a mortality rate lower than $2 \%$. However, almost $20 \%$ of attacks progress to acute and severe pancreatitis. The overall mortality rate of pancreatitis was $4 \%-7 \%(10)$. In acute pancreatitis patients, the mortality is associated with multi-organ dysfunction syndrome (MODS) and septic complications. Over the recent years, the main cause of mortality is MODS. The mortality in these patients occurs in 2 stages: the first week when systemic inflammatory response syndrome (SIRS) and MODS occur, and the late stage after 1-3 weeks following the MODS accompanied with infections $(5,16)$. There are many studies on the relationship of mortality or complications in different patients with heart diseases, cancer, stroke, peripheral vascular,renal disease, infection, respiratory, and acute diseases as well as normal patients and normal populations with the primary level of RDW 
A

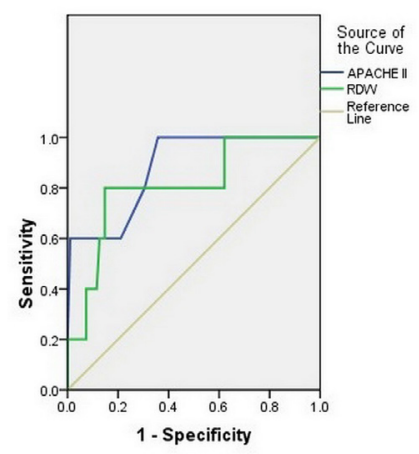

B

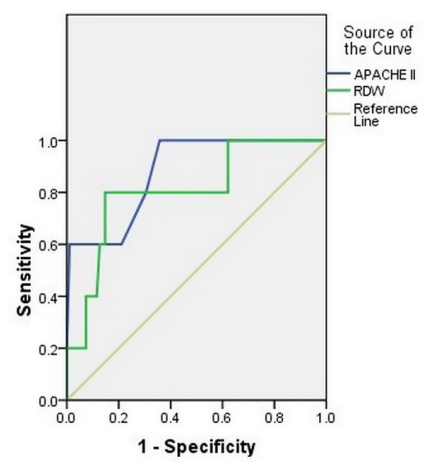

Figure 2. ROC for patients' RDW and APACHE II score based on predicting (A) admission complications and (B) mortality in patients .

(17-19). Most of these studies conducting survival analysis introduced RDW as a determinant variable of mortality in patients. Moreover, RDW has been introduced as a predictor of complications, such as heart failure in myocardial infarction, although studies could not predict the severity of cancer or stroke with RDW (20-24), but RDW strongly predicts the mortality in patients with known stroke (25). In their study, Senol et al concluded that the level of RDW upon the admission of patients with acute pancreatitis was a useful factor for determining the mortality rate in these patients (4). Zorlu et al examined the level of RDW and stated that RDW was a predictive factor in patients with cardiopulmonary disorders, including coronary heart disease, acute myocardial infarction (AMI), acute and chronic heart failure, and pulmonary hypertension, and the high level of RDW increased the mortality rate in these patients (6). Jo et al concluded that the primary level of RDW significantly correlated with the mortality rate in patients with severe sepsis and septic shock patients and was significantly higher in dead patients (7). Wang et al conducted a study on mortality rate in patients admitted to the ICU and found that the high level of RDW was more correlated with mortality (8). Our study results show that the cut-off point of RDW could not be determined in predicting the need for surgery and the need for admission to the ICU, while, the cut-off point of 14.55 for RDW with $80 \%$ sensitivity and $85 \%$ specificity was determined for predicting mortality and the cut-off point of 13.95 for RDW with $80 \%$ sensitivity and $71 \%$ specificity was determined for predicting admission complications. In this study, significant results were obtained only in determining the mortality and admission complications of patients on the basis of the initial level of RDW, while, RDW did not predict other outcomes. In our study, only 5 patients died. Also, our results revealed that the level of RDW in patients who were admitted to the ICU due to the severe symptoms or died due to the exacerbation of the disease was higher than that in other patients. This study was the second one, after Senol and colleagues' study (4), which showed the value of the primary level of RDW in determining mortality in patients with acute pancreatitis.

One of the limitations was the impossibility of investigating all the cases presenting to the emergency ward when collecting samples. Moreover, there was no control group due to the descriptive design of the study.

This study showed that the initial RDW level is an independent factor for predicting in-hospital mortality in pancreatitis but not for determining the need for surgery or admission to the ICU. However, further studies should be performed on a larger sample size and in other medical centers.

\section{Ethical issues}

Ethics Committee of Tabriz University of Medical Sciences approved this study (No. 8984). We obtained an ethical consent from all participating patients once they were briefed about all the conditions. During the study, the privacy of patients was quite considered.

\section{Authors' contributions}

PM and KSN carried out the design and coordinated the study, participated in most of the experiments and prepared the manuscript. MHS and MP provided assistance for all experiments. AFH and FR provided assistance in the design of the study, coordinated and carried out all the experiments and participated in manuscript preparation. All authors read and approved the content of the manuscript.

\section{Acknowledgments}

Researchers would like to thank the assistance of Deputy for Research and Technology, Tabriz University of Medical Sciences for supporting this project. The authors are grateful to all the health personnel and patients who participated in the study, in addition to the data collectors, supervisors and administrative staff of the emergency department of Imam Reza Hospital. This article was written based on dataset of Akbar Fadaei Haghi's specialty thesis. We would also like to express our sincere appreciation to Mr. Mehdi Talebi for his contribution to do this project. 


\section{References}

1. Fisher WE, Anderson DK, Bell RH, Saluja AK, Brunicardi FC. Pancreas. In: Brunicardi FC, Anderson DK, Billiar TR, eds. Schwartzs Principles of Surgery. 8th ed. New York: McGraw-Hill; 2005. p. 1231-40.

2. Wang X, Cui Z, Zhang J, Li H, Zhang D, Miao B, et al. Early predictive factors of in hospital mortality in patients with severe acute pancreatitis. Pancreas 2010; 39(1): 114-5. doi: 10.1097/MPA.0b013e3181b65dd5.

3. Yoldas O, Koc M, Karakose N, Kilic M, Tez M. Prediction of clinical outcomes using artificial neural networks for patients with acute biliary pancreatitis. Pancreas 2008; 36(1): 90-2. doi: 10.1097/MPA.0b013e31812e964b.

4. Senol K, Saylam B, Kocaay F, Tez M. Red cell distribution width as a predictor of mortality in acute pancreatitis. Am J Emerg Med 2013; 31(4): 687-9. doi: 10.1016/j. ajem.2012.12.015.

5. Song CS, Park DI, Yoon MY, Seok HS, Park JH, Kim HJ, et al. Association between red cell distribution width and disease activity in patients with inflammatory bowel disease. Dig Dis Sci 2012; 57(4): 1033-8. doi: 10.1007/ s10620-011-1978-2.

6. Zorlu A, Bektasoglu G, Guven FM, Dogan OT, Gucuk E, Ege MR, et al. Usefulness of admission red cell distribution width as a predictor of early mortality in patients with acute pulmonary embolism. Am J Cardiol 2012; 109(1): 128-34. doi: 10.1016/j.amjcard.2011.08.015.

7. Jo YH, Kim K, Lee JH, Kang C, Kim T, Park HM, et al. Red cell distribution width is a prognostic factor in severe sepsis and septic shock. Am J Emerg Med 2013; 31(3): 545-8. doi: 10.1016/j.ajem.2012.10.017.

8. Wang F, Pan W, Pan S, Ge J, Wang S, Chen M. Red cell distribution width as a novel predictor of mortality in ICU patients. Ann Med 2011; 43(1): 40-6. doi: 10.3109/07853890.2010.521766.

9. Naing L. Sample size for sensitivity and specificity studies. Available from: http://www.kck.usm.my/ ppsg/statistical_resources/samplesize_forsensitivity_ specificitystudiesLinNaing.xls.

10. Hemphill RR, Santen SA. Disorders of the Pancreas In: Marx JA, ed. Rosen's Emergency Medicine. Philadelphia: Elsevier Saunders; 2014. p. 1205-15.

11. Safari S, Rahmani F, Soleimanpour H, Ebrahimi Bakhtavar H, Mehdizadeh Esfanjani R. Can APACHE II score predict diabetic ketoacidosis in hyperglycemic patients presenting to emergency department? Anesth Pain Med 2014; 4(4): e21365. doi: 10.5812/aapm.21365.

12. Wu BU, Bakker OJ, Papachristou GI, Besselink MG, Repas $\mathrm{K}$, van Santvoort HC, et al. Blood urea nitrogen in the early assessment of acute pancreatitis: an international validation study. Arch Intern Med 2011; 171(7): 669-76. doi: 10.1001/ archinternmed.2011.126.

13. Anderson JL, Ronnow BS, Horne BD, Carlquist JF, May HT, Bair TL, et al. Usefulness of a complete blood count- derived risk score to predict incident mortality in patients with suspected cardiovascular disease. Am J Cardiol 2007; 99(2): 169-74. doi: 10.1016/j.amjcard.2006.08.015.

14. Yao J, Lv G. Association between red cell distribution width and acute pancreatitis: a cross-sectional study. BMJ Open 2014; 4(8): e004721. doi: 10.1136/bmjopen-2013-004721.

15. Kolber W, Sporek M, Dumnicka P, Kusnierz-Cabala B, Kuzniewski M, Gurda-Duda A, et al. Acute pancreatitis and red cell distribution width (RDW)I at early phase of disease. Przegl Lek 2013; 70(11): 916-9. [In Polish].

16. Carnovale A, Rabitti PG, Manes G, Esposito P, Pacelli L, Uomo G. Mortality in acute pancreatitis: is it an early or a late event? Jop 2005; 6(5): 438-44.

17. Makhoul BF, Khourieh A, Kaplan M, Bahouth F, Aronson D, Azzam ZS. Relation between changes in red cell distribution width and clinical outcomes in acute decompensated heart failure. Int J Cardiol 2013; 167(4): 1412-6. doi: 10.1016/j. ijcard.2012.04.065.

18. Hong N, Oh J, Kang SM, Kim SY, Won H, Youn JC, et al. Red blood cell distribution width predicts early mortality in patients with acute dyspnea. Clin Chim Acta 2012; 413(1112): 992-7. doi: 10.1016/j.cca.2012.02.024.

19. Braun E, Domany E, Kenig Y, Mazor Y, Makhoul BF, Azzam ZS. Elevated red cell distribution width predicts poor outcome in young patients with community acquired pneumonia. Crit Care 2011; 15(4): R194. doi: 10.1186/ cc10355.

20. Horne BD. A changing focus on the red cell distribution width: why does it predict mortality and other adverse medical outcomes? Cardiology 2012; 122(4): 213-5. doi: $10.1159 / 000341244$.

21. Kurt M, Tanboga IH, Buyukkaya E, Karakas MF, Akcay $A B$, Sen N. Relation of red cell distribution width with CHA2DS2-VASc score in patients with nonvalvular atrial fibrillation. Clin Appl Thromb Hemost 2014; 20(7): 687-92. doi: $10.1177 / 1076029613478157$.

22. Felker GM, Allen LA, Pocock SJ, Shaw LK, McMurray JJ, Pfeffer MA, et al. Red cell distribution width as a novel prognostic marker in heart failure: data from the CHARM Program and the Duke Databank. J Am Coll Cardiol 2007; 50(1): 40-7. doi: 10.1016/j.jacc.2007.02.067.

23. Tonelli M, Sacks F, Arnold M, Moye L, Davis B, Pfeffer M. Relation between red blood cell distribution width and cardiovascular event rate in people with coronary disease. Circulation 2008; 117(2): 163-8. doi: 10.1161/ circulationaha.107.727545.

24. Spell DW, Jones DV Jr, Harper WF, David Bessman J. The value of a complete blood count in predicting cancer of the colon. Cancer Detect Prev 2004; 28(1): 37-42. doi: 10.1016/j.cdp.2003.10.002.

25. Ani C, Ovbiagele B. Elevated red blood cell distribution width predicts mortality in persons with known stroke. J Neurol Sci 2009; 277(1-2): 103-8. doi: 10.1016/j. jns.2008.10.024. 